\title{
Understanding Corruption in Different Contexts
}

\author{
Richard Rose and Caryn Peiffer
}

\begin{abstract}
:
In their contribution entitled Understanding Corruption in Different Contexts, the authors Richard Rose and Caryn Pfeiffer discuss the meaning and standards of corruption by looking at countries in the Global North and Global South. They refer to fuzzy and broad definitions of corruption in circulation worldwide and emphasize the demand for an integrated explanation of corruption by following an interdisciplinary approach. The chapter offers a review of social scientists theories about causes and consequences of corruption followed by new findings and evidence from a comparison of 122 countries around the globe assessed by the Global Corruption Barometer and 176 countries compared by the Corruption Perception Index of Transparency International. Rose and Pfeiffer find that generalizations about corruption in countries grouped according to geography and culture are misleading. Variations in national context within continents are greater than differences between mean ratings of continents. A superficial comparison of the degree of corruption across continents and countries of the Global South and North is misleading. The authors suggest nine principles for reducing retail corruption with high practical value. In particular, they emphasize that reducing direct contact between public servants and citizens by delivering services electronically can result in more efficient public services at the grass roots and simultaneously lower the possibilities for corrupt behavior.
\end{abstract}

Keywords: Definitions of Corruption, Anti-Corruption Policies, Corruption Perception Index. Global Corruption Barometer, Large-N Comparison

\section{Introduction}

Social scientists offer a multitude of definitions of the word corruption and there is no agreement on a standard meaning. Without standards for defining these terms, the result is confusion. In countries where the payment of bribes for public services is not a matter of everyday life, the academic conclusion may be that the term is useless or even that there is no such thing as corruption. But it is a luxury to ignore corruption in countries where the illegal payment of money to get access to public services can affect millions of people who rely on government to deliver education, health care and personal security. Corruption can also affect the award of government contracts worth billions to those private enterprises and multi-national corporations that benefit.

How the process of governance is evaluated reflects the standards used to define corruption, as well as how public officials behave. When ordinary Russians describe politicians as corrupt they usually have in mind officials abusing their public office for private gains that can be worth billions of rubles. When Britons refer to politicians as corrupt, they often have in mind behaviour that would be unacceptable among friends, such as making misleading statements. When dictators in poor countries are accused of corruption by taking money in return for awarding public contracts to private enterprises owned by their relatives, they may claim they are simply following their country's traditional practice of supporting their extended family.

The first challenge of public policy is to define corruption in a sufficiently clear way that it can be used to diagnose the abuse of public authority and, where this is a problem, to make policy prescriptions to reduce corruption that wastes money and deprives citizens of benefits to which they are entitled by law. Making the definition of a concept relative to national context or loading it up with a dozen or more different meanings risks stretching it to the point at which it is no longer scientifically useful.

To compare good and bad governance in countries around the world today, a definition of corruption is needed that goes beyond accepting that whatever is done in a given national 
context is internationally acceptable. It is even more needed by intergovernmental organizations such as the World Bank, which annually spends many billions in trying to improve economic and social conditions in countries in which its efforts can be frustrated when its money wasted and spent corruptly.

\section{Corruption: A Word With Many Meanings}

Corruption is a behavioral relationship between governors and governed. A narrow definition of governance is that it is about relations within government between principals, who decide what government institutions do, and public officials who act as their agents in the process of governance (cf. Peters and Pierre, 2004). While these relationships are important for high-level politics, this focus ignores how public officials deal with the great mass of citizens living outside the national capital. Institutions provide the laws, money and public employees that produce public services, while governance determines the experience that ordinary people have when they deal with officials delivering these services. These outputs include both the "good" goods of public policy, such as education and health care, and necessary but not always welcome services, such as court judgments.

Corruption differs in impact between capital-intensive goods that cost many millions to produce, and public services that are retail in scale because they are relatively cheap to provide, such as birth certificates. Services also differ in who is involved. Capital-intensive activities such as building bridges or producing military aircraft involve a relatively small number of corporations that have the resources needed to produce such expensive high-tech goods. In countries where bureaucratic standards are weak, the prospect of big profits is an incentive for enterprises to offer big bribes for contracts and for groups of high-ranking politicians to accept them. Government negotiation of contracts for capital-intensive goods is handled over the heads of ordinary people.

Ordinary people are directly involved in retail services delivered by public employees based in schools, clinics and other public agencies in their community. Public officials have the power to decide whether or not a person is entitled to receive a desired service or excused from meeting an obligation. Bureaucratic laws and regulations set out in detail the procedures that public officials ought to follow when deciding whether a person is entitled or obligated to receive a service. The extent to which officials have discretion varies greatly between services. The decision about whether a woman is pregnant involves objective tests. A decision about whether a person has a mental illness entitling him or her to receive a disability benefit in cash or kind leaves officials with substantial discretion.

To describe governance in positivist language as the normal way in which public officials relate to citizens can be taken to mean that the way public officials usually behave is how they ought to behave. In countries where good governance tends to prevail, this can be a distinction without a difference. However, where officials often do not behave as they ought to, a positivist definition ignores the normative difference between good and bad governance. Where corruption is persisting, a behavioural characterization may interpret activities that appear corrupt by international standards as an equilibrium maintained by the holders of power delivering policies that benefit themselves and their supporters and that are accepted with resignation by people who lack the political influence to promote good governance (MungiuPippidi, 2015).

Socially constructed definitions. The meaning of corruption cannot be determined by citing whatever is recorded in a dictionary. It is socially constructed according to the context in which it is used and the normative standards of those using the term; these standards tend to differ between social scientists, journalists, and ordinary people. Review articles chronicle many different contemporary uses of the word (Kurer 2015). The number of meanings increases greatly when comparisons are made across time and space (see e.g. Heidenheimer and Johnston 2002, Part One).

The English word corruption is derived from the Latin corrumpere, something that fails to 
meet a particular standard. A computer program can be described as corrupt if it does not meet the standard set by the computer's operating system. Corruption has a family of meanings with a degree of kinship; it also has family disputes. Because corruption invariably has negative connotations, it tends to be used as a synonym for bad governance.

Contemporary social science favours reducing the meaning of corruption to a single numerical scale that makes corruption a matter of degree. The scale can then be used in quantitative statistical analyses testing theories of the causes and consequences of corruption. This ignores the need to name things before counting them or assigning them numbers. A legal approach divides activities into two categories, those that are corrupt and those that are not. It relies on written texts that specify illegal practices in the delivery of public services. The only numbers employed are those used in enumerating the clauses of a law. Transparency International's definition of corruption is: "the abuse of entrusted power for private gain" (www.transparency.org). Its anti-corruption glossary lists 60 entries with different examples of corruption; doing so undermines the concept having a clear and consistent meaning. Yet the significance of corruption for governance means that it cannot be abandoned.

We stipulate corruption as having two fundamental criteria: the violation of formal bureaucratic standards or the violation of informal normative standards about how public office-holders ought to behave. Formal bureaucratic standards are set out in laws and regulations. Violations of these standards can be assessed through normal legal processes and enforced by courts. Informal standards are norms about how governors ought to behave. These standards are 'soft' laws. They are social psychological expectations held in the mind rather than recorded in statute books. If there is a consensus within a society that a public official has broken an informal standard, then he or she can be punished for corrupt behaviour in the court of public opinion. A single political action can violate both standards.

When both formal and informal standards of political behavior are weak or lacking, then politicians decide for themselves how to behave. The breakdown of the Soviet Union led to the transformation of Communist societies by behavior that appeared corrupt to Western advisors but was justified on the grounds of the "primacy of surviving by mutual social favours" (Sajo, 2002, p.2; cf. Rose 2009, Chapter 5). An economic theory based on the premise that individuals pursue their own self-interest can lead to public officials profiting surreptitiously from the sale of state-owned assets such as oil or diamonds or even 'stealing the state' by transferring assets to a new breakaway entity that they control (Solnick 1998). Doing whatever is necessary to ensure survival is specially relevant in countries engaged in internal war. In the absence of a state with the effective power to enforce any standards, the optimal outcome is, in the words of an economist, "efficient predatory behavior in a lawless world" (Dabla-Norris 2002).

To describe the behavior of public officials as corrupt there must be laws formally setting standards that public officials ought to apply impartially when making decisions. In other words, public officials should behave like bureaucrats in a modern state (Weber 1947). If they do not, then their behavior is corrupt. In a political system that has not adopted the bureaucratic rules of a modern state, corruption in this sense cannot exist. If an official shows favoritism in appointing relatives and friends to public jobs for which they are not qualified, in a given political system such patronage may be considered normal. If an official is given money after delivering a benefit to an individual or waiving an obligation, in the absence of a law making this illegal, it is not bribery. Anthropologists describe this as a customary act of gratitude and economists as a rational transaction in which you get what you pay for.

Only by importing modern standards can customary behavior be described as corrupt. The introduction of bureaucratic institutions challenges the customary application of particularistic standards in which who you are and who you know is important to getting public services. Mungiu-Pippidi (2015, p.24) describes particularism as acceptable behavior in societies in which people expect officials with whom they share identities to favor their own kind. In the words of an Indian anthropologist (Gupta 1995, p.397), "a highly placed official who fails to help a close relative or fellow villager obtain a government position is often roundly criticized by people for not fulfilling his obligations to his kinsmen and village brothers". Although favoritism involves officials abusing bureaucratic standards, it is done not in exchange for 
money, but as an expression of solidarity ties with those whom they favor.

Even if an action does not break a law, if it violates an informal normative standard of behavior it can be labeled corrupt in the court of public opinion. Public officials tend to be held to higher normative standards than people in charge of private-sector enterprises in which making money is the standard that matters most. They are also held to higher standards than entertainment celebrities who shamelessly seek attention and judge their behavior according to the publicity that they gain.

Taking both legal and normative standards into account creates four different ways of evaluating whether public officials can be described as acting corruptly. Ideally, public services should be delivered in keeping with bureaucratic standards that stipulate under what conditions individuals are or are not entitled to receive a social benefit or obligated to comply with regulations. There is also informal agreement that impartiality, treating people in like circumstances in the same way, is it the right way to behave. When these two criteria are met, the outcome meets both standards of good governance. By contrast, a system of governance is doubly corrupt if officeholders violate laws for their own advantage and their behavior is inconsistent with the normative values of a society.

When legal and normative definitions produce conflicting assessments, calling something corrupt is in dispute. Behavior that is illegal may be tolerated when legal standards are inconsistent with informal practices of a society. For example, laws that define speeding at a level that most drivers think is below that needed to ensure safe driving are regularly violated. Traffic police are expected to tolerate speeding on an empty road if this does not create the danger of an accident. The violation of a law can also be informally tolerated if it is regarded as a relic of out-of-date moral standards for example, a law making same-sex relations illegal. In a country in which an authoritarian government represses critics, breaking repressive laws may be deemed a desirable weapon of subjects whose legal resources for opposition are weak.

Even if a public officially acts in accord with the law, their actions can informally be assessed as corrupt by informal normative standards. A governing party may accept a substantial sum of money from a business that acts in accord with laws about party finance that are written by politicians who benefit most from the loopholes that they contain. By definition this action is legal. However, if the government adds a special clause in a tax law that favours its financial donors, this will appear corrupt by the informal standards of public opinion. Likewise, politicians can be described as behaving shamefully if they proclaim standards in public and violate them in private, for example, emphasizing the importance of everyone paying taxes while sheltering their own income in a bank in a country with regulations that protect from exposure the bribes they receive.

Because corruption is a political issue, standards are often objects of political dispute. Politicians have the rhetorical skills to argue that accusations against them for corruption are false facts made up by their partisan opponents. Lawyers have professional skills to get a court to rule that there is nothing illegal in the way a politician has violated informal standards of behavior by taking money from a big business in exchange for favors. Even if evidence of breaking informal standards is acknowledged, if this does not lead to a conviction in a court of law, a politician can argue that a formal investigation has cleared him or her of blame and dismiss charges as politically motivated.

The multiple meanings of corruption are increased by the term being stretched to describe as wrong anything that a person does not like. However, as more and more activities are labeled corrupt, the umbrella term becomes a vast shopping mall offering so many different definitions that the word loses any meaning.

\section{Social Scientists Differ in Explaining Corruption}

The variety of issues raised by corruption requires an interdisciplinary approach, but social scientists are divided into disciplines with different intellectual frameworks and methods. This results in a plurality of explanations that give priority to the assumptions of a single discipline 
rather than an integrated explanation. The following paragraphs review different propositions about major causes of how corruption varies between countries and within a country, between individuals. Discussing each explanation separately for purposes of exposition does not mean that they are mutually exclusive. A multiplicity of explanations may be empirically significant; however, the scale of their impact on corruption can differ substantially.

The history of a country is a given, and decisions and practices institutionalized in the past have created formal and informal procedures that influence governance today. This makes it difficult for reforms to alter established routines by enacting new laws. When international aid agencies seek to reduce corruption in developing countries by introducing legal and bureaucratic institutions, they have often met resistance from national political elites benefiting from traditional practices inconsistent with contemporary bureaucratic standards.

Theories of path-dependence explain the persistence of both good and bad forms of governance (Pierson 2004). The persistence of a low level of corruption in Northern Europe is explained as a consequence of a nineteenth-century history in which structural changes in traditional methods of administration were replaced by bureaucratic institutions. What Alina Mungiu-Pippidi (2013) has called 'becoming Denmark', that is, achieving a high standard of governance, was a very lengthy process. Countries that began socializing public officials into bureaucratic practices long before mass welfare state services were introduced should therefore be low in corruption. By contrast, if major social benefits were introduced while traditional customs such as clientelism were still practised, this can account for a government being deemed corrupt today. Historical differences can create a stable equilibrium that maintains good governance in Scandinavia and corrupt governance in places such as the successor states of the Soviet Union (cf. Hellman 1998).

Theories of political culture explain the presence of good or bad governance as a consequence of collective norms. Each new generation is socialized into a common understanding about how government works and the standards that adults ought to apply in their relations with public officials. Insofar as this happens, people regard the way in which government works as normal in both the behavioural and the normative senses. Since cultural norms develop in a particular national and historical context, what is regarded as normal in South Africa can be different from what is regarded as normal in Sweden. In a country with relatively good governance, people are prepared to wait patiently in a queue for a service or to accept a refusal to provide it as fair, and cases of corruption are seen as exceptions to the rule. By contrast, in a culture where favouritism and bribery is regarded as a fact of life, behaviour that appears corrupt by universalistic standards appears normal (cf. Persson et al. 2013; Manzetti and Wilson 2007).

Institutional theorists reject the idea of classical philosophers that the absence of individual virtue is the primary cause of corruption. Any tendency of politicians or their agents to practice corruption needs to be subject to monitoring by an independent audit office; an independent legal team with the power to prosecute those who break laws; and courts with the power to enforce laws against corruption. Theories of democratic institutions explain the absence of corruption as due to free elections giving voters the power to decide who governs. If the principals of a democratic government tolerate corruption, voters have an opportunity to vote them out of office. In anticipation of the threat of losing office, governors are expected resist opportunities to abuse their powers for personal gain (cf. Potter and Tavits,2011).

Theories of sociology explain governance relationships as reflecting social status. Who you are and how you are perceived by others, affects the way in which you are treated by public officials. Class differences in individual income and education may result in people of higher social status being more likely to experience good governance and those lower down the social ladder being bullied to pay bribes. People can protect themselves from the effect of corruption in a particular public service by having no contact with it. Individuals without children are not at risk of corruption in education because they have no children in school. However, older people are vulnerable to corruption in the health service because they cannot do without health care.

Social psychologists stress that expectations that people have about how they will be treated 
when seeking a public service explain how they behave. Expectations about how government ought to work and perceptions of how public officials actually behave can cue people to respond in opposing ways. People would like to experience good governance but may perceive political institutions as corrupt. If this is the case, they will be more ready to understand hints from public officials asking for bribes as a condition of giving them what they want.

In political economy it is a given assumption that economic conditions affect how a country is governed (see e.g. Rose-Ackerman and Soreide 2011). However, this leaves open what specific features of an economy are important. A high correlation between a country's Gross Domestic Product (GDP) per capita and its rating on the Corruption Perceptions' Index is often interpreted to mean that the more prosperous a country is, the lower its level of corruption. However, when Gross Domestic Product per capita is included in a multivariate statistical analysis testing potential determinants of national level corruption, it fails to achieve statistical significance (Rose and Peiffer 2015, Table 6.2). Moreover, there are good theoretical reasons for interpreting economic prosperity as a consequence rather than a cause of a low level of corruption (cf. Lambsdorff 2007, p.72ff). Freedom from corruption can boost economic growth. Enterprises can invest with confidence because they are not harassed by public officials administering economic regulations in ways that are inefficient and arbitrary and require the payment of bribes.

There are theoretical reasons for expecting specific economic conditions to encourage corruption. The national government of a country rich in natural resources will enjoy a large inflow of money from multi-national corporations wanting to extract its resources and export them at a profit. Corrupt governors may demand large payments be made to their private bank accounts overseas in exchange for giving them permission to do so. Moreover, in a country that is at a low level of economic development, foreign aid becomes a very importance source of national income, and governors may want to divert a proportion of foreign aid for their private benefit, thus reducing the amount available to invest in actions of public benefit such as building roads and hospitals.

Rational-choice economic theories disregard normative values; they assume that individuals are self-interested actors ready to pay for what they want. Where there is a choice between providers, people do not have to wait indefinitely in a queue or pay a bribe to receive what may be an inferior service. Instead, they may turn to an alternative provider, whether a not-for-profit or a profit-making enterprise, if they can afford to do so. Since many public services are monopolies, in a system of bad governance the only choice that individuals may have is that of paying a bribe or going without a service they want. In such circumstances, a simple costbenefit calculation can determine whether a bribe is paid.

A public policy explanation emphasizes that differences between services are important in determining whether a service is more or less likely to involve corruption. Collective goods such as military defense and the rate of inflation affect every individual and institution in a society. In the language of economics, collective goods are non-excludable, because everyone in the population is included in their impact (Samuelson 1954). Since this is the case, the officials making collective goods decisions cannot collect a bribe from individuals wanting to avoid their effects. Since every citizen shares in the risks of modern war, the only way in which a person can avoid this is to leave the country.

Although there are lots of theories offering explanations of corruption, there is limited statistical testing of the extent to which their hypotheses are supported by empirical analysis. One reason is that many do not specify clear testable links between cause and effect. Relatedly, many forms of corruption are portrayed as part of a complex syndrome of bad governance (Johnston 2014). Case studies of villages by anthropologists or of corrupt behavior by elites can be insightfully drawn from first-hand observation. However, narrowly focused case studies are often not fitted into a broader theoretical framework. Testing alternative theories of corruption requires comparable data about variations in national context, individual attributes and different types of public services (see Rose and Peiffer 2019, Chapters 3-5).

Capital-intensive corruption differs between continents and within, as show by the Corruption Perceptions Index (CPI) of Transparency International 
(@https://www.transparency.org/research/cpi). In recognition of uncertainties about the reliability and validity of any single source of evidence, the CPI uses multiple sources with different ways of making up its composition rating of a country. It places each country on a scale ranging from 0 to 100 ; this permits a far greater degree of differentiation than sorting countries into two categories, those that are corrupt and those that are not. Of the 176 countries assessed in the 2016 Corruption Perceptions' Index, Denmark and New Zealand have the highest rating, 90, while Somalia is lowest, 10. There is a tendency for bad governance to be more common; the median country has a CPI rating of 38, significantly closer to the most corrupt country than to the highest-rated country.

Comparing countries around the globe shows that generalizing about corruption in countries grouped according to geography or culture is misleading (Figure 1). Variations in national context within continents are greater than differences between the mean rating of continents. In Asia there is a spread of 72 points between Singapore and North Korea.

Asian values are neither conducive to corruption nor to high levels of integrity (Fukuyama 2001). African ratings likewise reject generalizations about continent-wide African cultural values (Ekeh 1975), because there is a range of 50 points between the CPI ratings of Botswana and Somalia. The range between countries in Latin America, the Middle East and North Africa (MENA) is likewise large. The successor states of the Soviet Union and their Central Asian neighbors show the least variation. This reflects the common experience of generations of having been governed in accord with the Marxist-Leninist principles for generations rather than bureaucratic procedures.

\section{Fig. 1 Big Variations in Corruption within Every Continent}

High CPI ratings are not confined exclusively to countries with European values and culture. Among European Union countries, there is a spread of 49 points between the highest-ranking country, Denmark, and Bulgaria, and 46 points between Denmark and Greece. Singapore has a better CPI rating than 24 member states of the European Union. Of the 68 countries that have a better rating than the lowest EU member states, 32 are developing or newly developed countries from outside Europe and the Anglo-American world.

There are also big differences in the risk of an individual paying a bribe. Contact is a necessary but not sufficient condition for this to happen. During the year more citizens have contact with the output side of politics, public services, than with the input side, voting for MPs. On every continent almost three-quarters annually have contact with at least one major service. Notwithstanding big differences in the economic capacity of governments, the extent of contact differs very little across continents. The average ranges from 78 percent in Asia to 69 per cent in formerly Communist EBRD countries.

Aggregate labeling of countries as corrupt implies that virtually everyone there who contacts public services pays a bribe. However, this is not the case, according to the evidence of the Global Corruption Barometer survey of 155,122 individual respondents in 122 countries around the globe (see Rose and Peiffer 2019, Chapter 4). The payment of bribes is confined to a minority of people. In West European countries an average of only two per cent reported paying a bribe in the past year. At an average level of 23 per cent paying a bribe annually, the Middle East and North Africa (MENA) is the region with the highest percent of bribe payers, with Asia close behind at 21 percent. Yet even where bribery is high, it is the annual experience of less than half the population. Among the 73 countries surveyed in Asia, Africa and Lain America, there were only four-Haiti, India, Vietnam and Liberia-in which a majority of respondents reported paying a bribe in the past year. On average, the Global Corruption Barometer found that bribery affects 18 per cent of a country's population each year (Fig. 2).

\section{Fig. 2 Bribery Varies Between and Within Continents}

Conventional geographical categories group together countries with very different levels of 
grass-roots bribery. The gap is greatest in Asia, a difference of almost 61 percentage points between India and Vietnam compared to Japan. It is least among the 15 old member states of the European Union, where the range is just under seven percent between Greece and two Nordic states, Sweden and Finland. In the new EU member states, the legacy of Communism increases bribery, rising to 22 percent in Lithuania but as low as two per cent in Slovenia.

Bribery varies between services too. Generalizations about corruption in public services imply that bribery is much the same for every service. This is not the case. The 2016 Global Corruption Barometer found that bribes are most often paid for the health service and for permits (Table 1). By contrast, the fewest people pay bribes for court services. The chief reason is that far fewer people have, or want to have, contact with the courts than with health and education. Controlling for contact gives a different rank order. Among people who contact the service, almost one-quarter pay bribes to the courts and to the police. The apparent high level of bribery for health and education services is because these are much needed and used services. After controlling for contact, the percentage of users paying a bribe for health care or education is significantly lower than that of people paying bribes to law-enforcement officials.

\section{Table 1 Bribery For Services After Controlling For Contact}

The more contacts people have with public services, the more likely they are to pay at least one bribe, but the increase is not proportional. Among GCB respondents using one service, 14 per cent pay a bribe. However, when the number of services contacted doubles, the proportion paying a bribe increases by only one-quarter and when it quadruples, the proportion paying bribes just doubles. Among heavy users of public services, the median respondent paid a bribe for only one service (see Rose and Peiffer 2015, Fig. 4.4).

Altogether, the experience that individuals have when contacting grass-roots officials reflects a combination of three sets of influences: differences between people, between national contexts, and between specific public services (Rose and Peiffer 2019; Chapter 5). The need to contact public services such as education differs with stages in an individual's life cycle. The institutions that deliver these services differ in their national history and contemporary context. Differences between public services such as health care and policing affect whether an individual pays a bribe for one service but not another.

\section{Reducing Corruption}

Politicians who win control of government with a promise to get rid of corruption are tempted to believe that their victory removes all the obstacles that are a legacy from their predecessors. However, overcoming obstacles to the reform of bad governance requires patience. Corruption in the body politic is a phenomenon that can take many forms. The diagnosis of corruption usually focuses on characteristics that are pervasive throughout the body politic as a whole. Prescriptions based on such a diagnosis do not take into account differences between public services. In order to reduce corruption, each form requires a diagnosis that identifies its distinctive characteristics, which part of the body politic it affects, and what its specific causes are. Without doing so, any prescription will tend to fall back on general recommendations that have no specific application to the corrupt delivery of a particular public service.

When individuals and business enterprises pay bribes, they are not paid for public services as a whole. Bribes are paid to obtain a specific public service and services differ in what is delivered and how much they are vulnerable to corruption. Public services delivered to individuals at the grassroots are vulnerable to bribes being paid far from the sight of policymakers in the national capital. By contrast, capital-intensive services are delivered by decisions about contracts made by high-level policymakers in the national capital.

Capital-intensive goods such as airports and electricity generating stations are lumpy not only in physical terms but also economically. A large chunk of money is required to construct them. By contrast, retail public services such as a driving licence or passport are literally 
pocket-sized and cheap to produce. The scale of capital-intensive projects makes it difficult for outsiders to evaluate whether paying hundreds of millions or a billion is a fair price to build a dam or a power station or whether it has been inflated to cover the cost of bribes that can be hidden behind opaque entries in a lengthy and complex budget. The individuals who make the decisions that commit their government to approve contracts paying millions to a private enterprise do not bear the cost. It is met from tax revenue and borrowing; in developing countries foreign aid can also bear a portion of the cost.

The supply of many capital-intensive goods is globalised, because of the amount of capital and technical skills required to produce such goods as military aircraft or complex computer systems. Intergovernmental organisations such as the United Nations promote codes of conduct that stigmatise trans-national corruption. But such codes normally lack legal sanctions, and any notional reputation loss an enterprise incurs for shadowy dealings is more than offset by the profits from getting big-bucks contracts. When capital-intensive corruption is trans-national, this makes it difficult for a single national government to prevent it. Business enterprises determined to win contracts if need be by hook or by crook can pay bribes to foreign bank accounts of consultancy firms or family members acting as agents of corrupt policymakers in other countries. Anglo-American countries have adopted laws making it illegal for multinational corporations based in their jurisdiction to pay bribes to foreign government officials and imposing large fines as and when such behaviour is revealed. National and intergovernmental aid agencies providing grants to finance capital-intensive projects have the right to monitor how aid money is spent and, if the political will is there, to suspend payments if evidence of corruption is revealed.

At the grassroots the most effective way to reduce corruption is not by local protests but by national policymakers using their formal powers to disrupt laws and institutions that give corrupt local officials opportunities to use their public office for private gain. Table 2 sets out nine principles for reducing corruption in the retail delivery of services at the grass roots. Given differences between services, some will apply to multiple services, and some services will be vulnerable to attack in more than one way.

\section{Table 2 Nine Principles For Reducing Retail Corruption}

Applying principles to reduce grass-roots corruption does not require a change in the hearts and minds of public officials. They require such things as removing the need to pay bribes to some public officials by abolishing their post. Face-to-face contacts between claimants and officials can be eliminated by introducing computers that enable individuals to get what they want by the on-line completion of forms that follow bureaucratic rules consistent with good governance. Onerous laws and regulations requiring permits and licences that give officials opportunities to collect bribes can be repealed. Such actions not only reduce opportunities for bribery but also increase the efficiency and ease of using public services.

Breaking the low-level equilibrium trap that maintains a national economy at a subsistence level requires disruptive action to start a progressive process of improvements (Hirschman, 1963). A strategy to disrupt corruption requires policymakers to make a visible and substantial change that can establish a political momentum leading to more changes. A bonfire of unpopular regulations that low-level public officials may use to extract bribes from ordinary people nationwide can stimulate public support. Introducing on-line services that people can access using free apps on their mobile phones cuts out public officials entirely. To be effective, disruptive changes must be targeted at particular services. Doing so will not bring about acrossthe-board abolition of corruption in all services in a world in which bribery is the price that 1.8 billion people pay each year for access to public services. Any actions that reduce bribery and increase the quality of public services is better than no progress and removing the burden of bribery from ten per cent of those who now pay bribes will benefit 180 million people annually.

\section{References}


Dabla-Norris, Eram. 2002. A Game Theoretic Analysis of Corruption in Bureaucracies. In George T. Abed and Sanjeev Gupta, eds. Governance, Corruption, and Economic Performance. Washington, DC: International Monetary Fund, 111134.

Ekeh, Peter P. 1975. Colonialism and the Two Publics in Africa: A Theoretical Statement. Comparative Studies in Society and History, 17, 1, 91-112.

Fukuyama, Francis. 2001. Asian Values in the Wake of the Asian Crisis. In Farrukh Iqbal and John-Il You, eds. Democracy, Market Economics and Development. Washington DC: World Bank, 149-168.

Gupta, Akhil. 1995. Blurred Boundaries: The Discourse of Corruption, the Culture of Politics, and the Imagined State. American Ethnologist, 22, 2, 375-402.

Heidenheimer, Arnold J. and Johnston, Michael, (eds.). 2002. Political Corruption: Concepts and Contexts, 3rd edition, New Brunswick, NJ: Transaction Publishers.

Hellman, Joel S. 1998. Winners Take All: The Politics of Partial Reform in Postcommunist Transitions, World Politics, 50, 203-234.

Hirschman, Albert. 1963. Journeys toward Progress. New York: Twentieth Century Fund.

Johnston, Michael. 2014. Corruption, Contention and Reform: the Power of Deep Democratization. New York: Cambridge University Press.

Kurer, Oskar. 2015. Definitions of Corruption. In Paul M. Heywood, ed. Routledge Handbook of Political Corruption. Abingdon: Routledge, 30-41.

Lambsdorff, Johann Graf. 2007. The Institutional Economics of Corruption and Reform. Cambridge: Cambridge University Press.

Manzetti, Luigi and Wilson, Carole J. 2007. Why Do Corrupt Governments Maintain Public Support?, Comparative Political Studies, 40, 8, August, 949-70.

Mungiu-Pippidi, Alina. 2013. Becoming Denmark: Historical Designs of Corruption Control, Social Research, 80, 4, 1259-1286.

Mungiu-Pippidi, Alina. 2015. The Quest for Good Governance: How Societies Develop Control of Corruption. Cambridge: Cambridge University Press.

Persson, Anna, Rothstein, Bo, and Teorell, Jan. 2013. Why anticorruption reforms fail: systemic corruption as a collective action problem. Governance, 26, 3, 449-471.

Peters, B. Guy and Pierre, John. 2004. Multi-Level Governance and Democracy: A Faustian Bargain? In Ian Bache and Matthew Flinders, eds., Multi-Level Governance, Oxford: Oxford University Press, 78-89.

Pierson, Paul. 2004. Politics in Time: History, Institutions and Social Analysis. Princeton: Princeton University Press.

Potter, Joshua D. and Tavits, Margit. 2011. Curbing Corruption with Political Institutions. In Rose-Ackerman, Susa and Soreide, Tina, eds. International Handbook on the Economics of Corruption. Cheltenham: Edward Elgar, 52-80.

Rose, Richard, 2009. Understanding Post-Communist Transformation: A Bottom Up Approach. London and New York: Routledge.

Rose, Richard and Peiffer, Caryn. 2015. Paying Bribes for Public Services: A Global Guide to Grass-Roots Corruption. Basingstoke: Palgrave Macmillan.

Rose, Richard and Peiffer, Caryn. 2019. Bad Governance and Corruption. London: Palgrave Macmillan and Springer Nature. 
Rose-Ackerman, Susan and Soreide, Tina, eds. 2011. International Handbook on the Economics of Corruption. Cheltenham: Edward Elgar, Volume 2.

Sajo, Andras, 2002. Clientelism and Extortion: Corruption in Transition. In Stephen Klotkin and Andras Sajo, eds. Political Corruption in Transition: a Sceptic's Handbook. Budapest: Central European University Press, 1-22.

Samuelson, P. 1954. The Pure Theory of Public Expenditure. The Review of Economics and Statistics. 36, 4, 387-389.

Solnick, Steven L. 1998. Stealing the State: Control and Collapse in Soviet Institutions. Cambridge, MA: Harvard University Press.

Weber, M. 1947. The Theory of Social and Economic Organization. Glencoe, Il.: The Free Press. Translated by A.M. Henderson and Talcott Parsons. 


\section{Tables and Figures}

\section{Fig.1 Big Variations in Corruption Within Every Continent}

Figure 3.1 BIG VARIATIONS IN CORRUPTION WITHIN EVERY CONTINENT

Corruption Perception Index

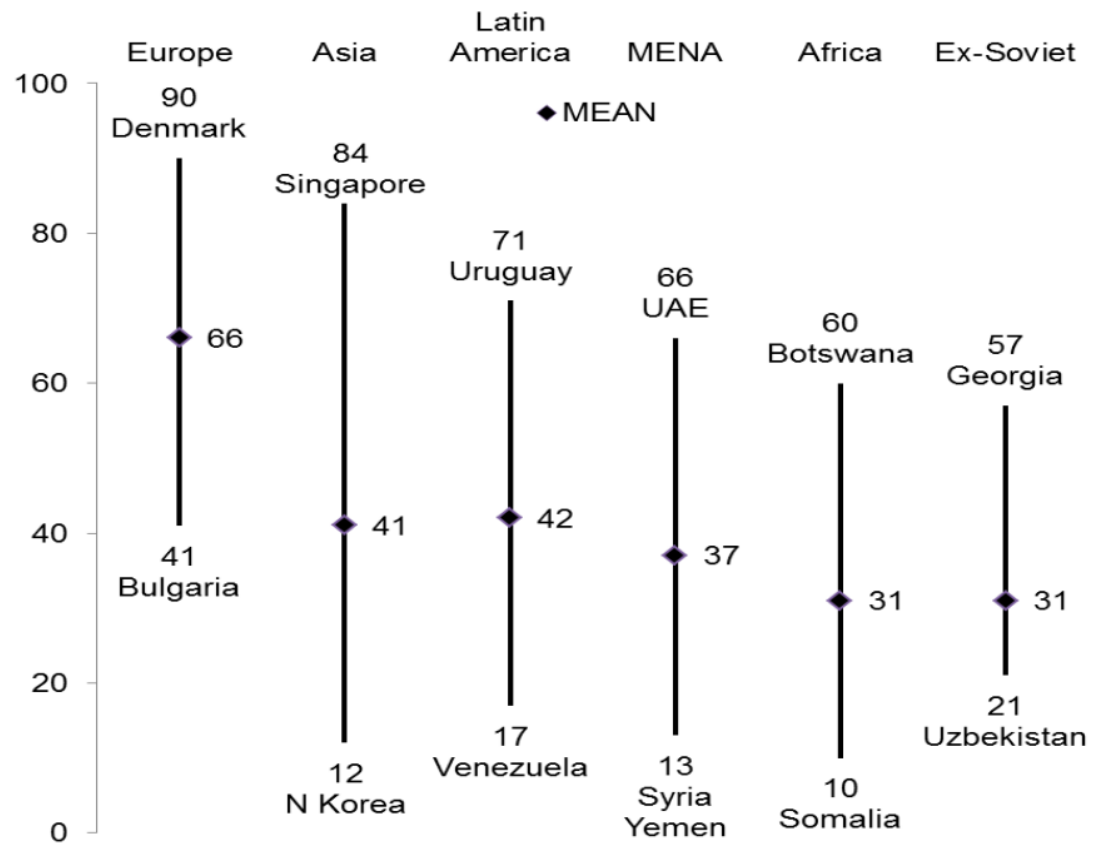

Source: Transparency International Corruption Perceptions Index for 176 countries, 2016. Anglo-American countries: New Zealand, 90, Canada, 82, Australia, 79 and the United States, 74.

Sources: Transparency International Corruption Perception Index for 176 countries, 2016. Anglo-American countries: New Zealand, 90, Canada, 82, Australia, 79 and the United States, 74. As reported in Rose and Peiffer 2019, Fig. 3.1. 


\section{Fig. 2 Bribery Varies Between And Within Continents}

Figure 4.3 BRIBERY VARIES BETWEEN AND WITHIN CONTINENTS

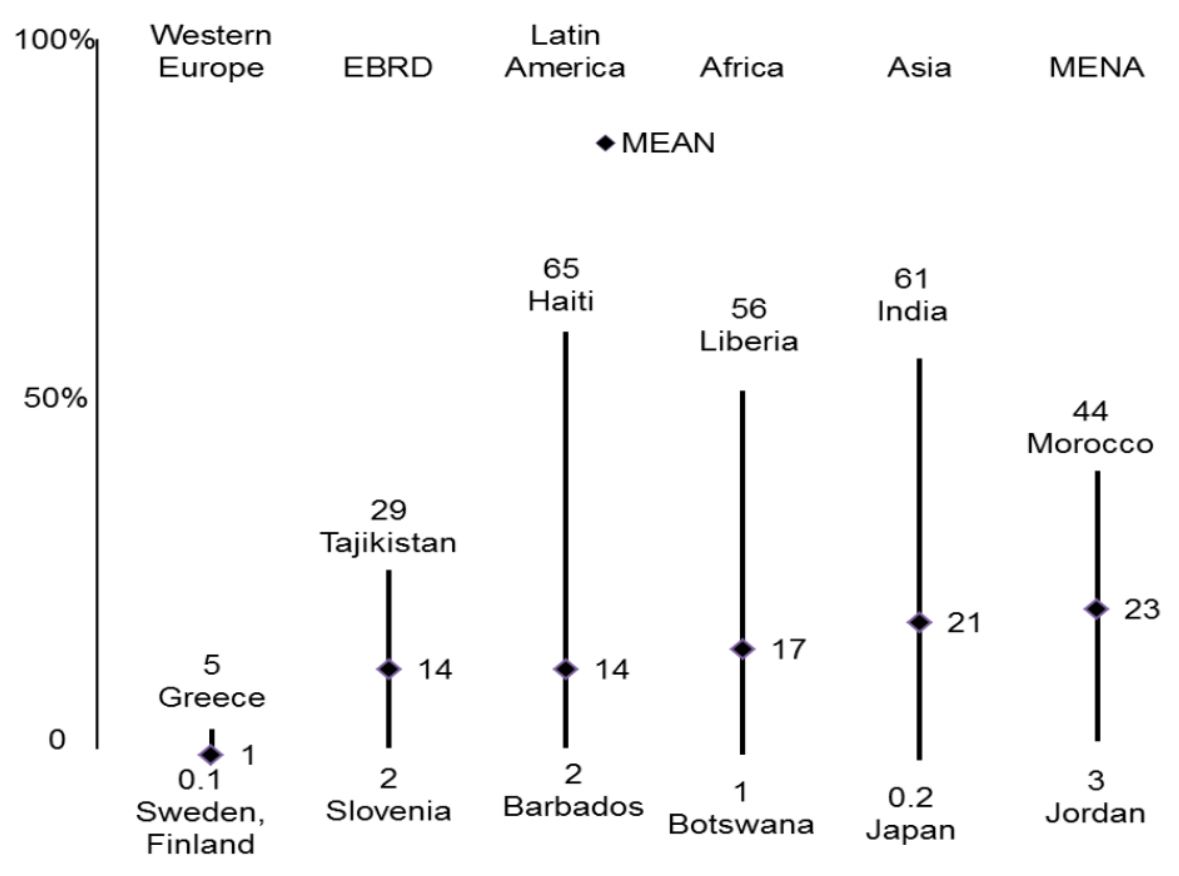

Source: Global Corruption Barometer 2016 as reported in Rose and Pfeiffer 2019, Fig. 4.3.

Table 1 Bribery For Services After Controlling For Contact

\begin{tabular}{l|lll|ll}
\hline & $\begin{array}{l}\text { No } \\
\text { Contact }\end{array}$ & $\begin{array}{l}\text { Contact, No } \\
\text { bribe }\end{array}$ & $\begin{array}{l}\text { Contact, } \\
\text { Bribe }\end{array}$ & $\begin{array}{l}\text { Bribe } \\
\text { Contact }\end{array}$ \\
\hline Health & 42 & 49 & 9 & 16 \\
Education & 64 & 31 & 5 & 14 \\
Permits & 61 & 32 & 7 & 18 \\
Police & 75 & 19 & 6 & 24 \\
Courts & 87 & 10 & 3 & 23 \\
\hline
\end{tabular}

Source: Global Corruption Barometer, 2016, as reported in Rose and Pfeiffer 2019, Table 2 


\section{Table 2 Nine Principles For Reducing Retail Corruption}

Repeal unnecessary laws, regulations and processes that facilitate the collection of bribes.

Increase the use of objective criteria for deciding eligibility for receiving services.

Use computers to reduce citizens having to come into contact with public officials.

Monitor entitlements and the delivery of services electronically.

Give citizens easy access to public records about themselves.

Supply services at a level that matches what citizens are entitled to and what the state is obligated to provide.

Give citizens a publicly funded choice between obtaining a service from state or non-state organisations.

Legalise payments for some public services.

Align public laws with informal standards.

Source: Summarised from Rose and Pfeiffer 2019: Chapter 9. 